\title{
Work of the NHS England Youth Forum and its effect on health services
}

\author{
Lisa Whiting, Sheila Roberts, Julia Petty et al
}

\section{Citation}

Whiting L, Roberts S, Petty J et al (2018) Work of the NHS England Youth Forum and its effect on health services. Nursing Children and Young People. doi: 10.7748/ncyp.2018.e1074

\section{Peer review}

This article has been subject to open peer review and checked for plagiarism using automated software

\section{Correspondence}

l.whiting@herts.ac.uk

\section{Conflict of interest}

This study was funded by NHS England

\section{Acknowledgement}

The authors are grateful to the young people who participated in this study and would like to thank them.

\section{Accepted}

24 April 2018

\section{Published online}

June 2018

\begin{abstract}
Aim To examine the role of members of the NHS England Youth Forum (NHSEYF) and the strategies used to influence health service provision for children and young people.

Method An evaluative mixed-methods study was commissioned by NHS England and undertaken by the University of Hertfordshire between July 2015 and September 2016. Data collection comprised activity logs, a form of questionnaire, and semi-structured interviews.
\end{abstract}

\begin{abstract}
Findings The analysis of the activity logs revealed that the young people were undertaking a wide range of activities across England. Seven themes emerged from the interviews: the young people; motivation; commitment; community (the local area as well as a community spirit); knowledge experts; youth workers; and funding. In summary, the members of the NHSEYF were committed to their role and their work was having a positive effect on health service provision.
\end{abstract}

Conclusion The NHSEYF has developed rapidly and successfully. It is enabling the voice of young people to be heard.

\section{Author details}

Lisa Whiting, professional lead, children's nursing, University of Hertfordshire, England; Sheila Roberts, senior lecturer, children's nursing, University of Hertfordshire, England; Julia Petty, senior lecturer, children's nursing, University of Hertfordshire, England; Gary Meager, senior lecturer, children's nursing, University of Hertfordshire, England; Kath Evans, experience of care lead, maternity, infants, children and young people, NHS England, London, England

\section{Keywords}

adolescents, child health, Department of Health, health policy, NHS England, Public Health England

\section{Aim}

The aim of this study was to examine the role of members of the NHS England Youth Forum (NHSEYF) and the strategies used to influence health service provision for children and young people.

\section{Introduction}

NHS England (2015) stated that a youth forum exists to 'represent the views of young people' and to 'contribute to improving and developing services for young people'.

While little previous research has focused on youth forums and/or councils, two studies are noteworthy. Matthews (2001) undertook a survey of four youth councils in the East Midlands, England. A total of 63 young people participated in either an individual semi-structured interview or a focus group to gain insight into their perceptions of being members of a youth council. The research identified several positive aspects, including improved appreciation of local issues, the ability to make a difference as well as personal development.

However, several challenges were also acknowledged:

I The associated bureaucracy.

" Lacking the required authority.

» Being tokenistic.

» Lack of time to complete the intended outcomes.

» Lack of members from diverse backgrounds.

» Not being wholly representative of the young people's views.

The study concluded that consideration needed to be given to the facilitation of youth councils, especially the 'initiation, the process and the outcome of young people's participation' (Matthews 2001). 


\section{Permission}

To reuse this article or for information about reprints and permissions, please contact permissions@rcni.com
Collins et al (2016) undertook research that focused on youth councils in an urban area of the US. The participants were adult representatives with one person from each of 24 neighbourhoods being interviewed. Several findings emerged: the young people participated in a breadth of activities and it was thought that this benefited the needs of the local community and the youth population. Those interviewed highlighted positive outcomes of having a youth council, such as influencing policy.

Nevertheless, the need to engage a broader range of young people was raised as an area for further consideration. Collins et al (2016) recognised the potential advantages of youth councils, but commented that they 'remain limited in practice and the research base is underdeveloped'.

\section{The NHS England Youth Forum}

The NHSEYF was established in 2014. It now comprises 25 members aged 13-25 years from across England. The members are encouraged to express their views about a range of health issues and to be involved in decision-making. The forum works closely with NHS England, Public Health England and the Department of Health and Social Care, which facilitates the hearing of the young people's 'voice'. The dayto-day management of the NHSEYF has been devolved to the British Youth Council (BYC).

Further details about the NHSEYF and
Figure I. The activity log

An examination of the work of the NHS England Youth Forum Activity Log, for the period: $1^{1 \text { st }}-31^{\text {st }}$ October 2015

Name:

Gender (please tick) Male [ ] Female [ ]

Home (please specify your town or village and area in England):

Day to day activity (for example, school or college or University or work or volunteer):

Membership of other organisations or youth forums (for example, Youth Parliament - please name):

\begin{tabular}{|l|l|l|l|l|}
\hline $\begin{array}{l}\text { NHS England Youth } \\
\begin{array}{l}\text { Forum activity } \\
\text { (please describe) }\end{array}\end{array}$ & $\begin{array}{l}\text { In what capacity } \\
\text { are you doing this } \\
\text { activity? }\end{array}$ & Date(s) & $\begin{array}{l}\text { Length of } \\
\text { time }\end{array}$ & Venue \\
\hline
\end{tabular}

its work can be found at england.nhs.uk/ participation/get-involved/how/forums/ nhs-youth-forum

\section{Method}

A mixed-methods approach was used to enable different perspectives to be appreciated (Moule and Goodman 2014). Greene et al (1989) suggested that there are five main reasons for the use of mixed methods: initiation, expansion, triangulation, complementarity and development. Complementarity (quantitative and qualitative approaches are used to examine overlapping as well as different aspects of a phenomenon) and development (the successive use of quantitative and qualitative methods - the former informing the latter) were drawn on for this study, therefore increasing the richness and depth of the data collection.

An activity log, a form of questionnaire (Figure 1), was designed after consultation with members of the NHSEYF at one of their residential weekends in June 2015. The logs contained quantitative data about the activities that the NHSEYF members undertook as part of their NHSEYF role.

Narrative inquiry informed the qualitative data collection that was undertaken through semi-structured interviews. This interpretive methodological approach enables the capture of personal and human dimensions. In addition, it takes into account the relationship between the individual experience and the cultural context (Clandinin and Connelly 2000).

\section{Participant recruitment}

Purposive sampling was used as it allows for specific predefined criteria and the selection of information-rich participants (Palinkas et al 2015). The participants sought were the 25 members of the NHSEYF.

\section{Data collection}

After the receipt of ethical approval, an information sheet was sent by a BYC employee to all the NHSEYF members inviting them to complete activity logs for a three-month period between October and December 2015. The NHSEYF members received monthly emails from the BYC employee inviting them to complete the activity log for that calendar month. Logs documenting activities undertaken as well as the length of time, location and cost were completed by nine members and returned to the research team.

Information about the interviews was also distributed by the same BYC employee to all members of the NHSEYF. A mutually 
convenient date, time and location for each interview was negotiated with the young people who wished to participate. Eight interviews took place between June and August 2016 and lasted for between 17 and 45 minutes. To maintain consistency, one research team member conducted all the interviews.

Data analysis

Descriptive statistics were used to analyse the quantitative data from the activity logs.

Creswell (2012) offered the six-stage 'bottom-up' qualitative process of data analysis framework:

1. Data collection.

2. Interview transcription.

3. Repeated reading of the transcripts.

4. Assignment of codes to key elements of the transcripts.

5. Coding to identify descriptions for later use in the final report.

6. Coding to reveal key themes.

These stages were applied to the interview transcripts. Analysis involved first listening to the interview recordings and then reading the transcripts several times. Coding was used to facilitate the emergence of seven themes.

\section{Ethical considerations}

Ethical approval was granted by the University of Hertfordshire (protocol numbers: HSK/ SF/UH/00119; HSK/SF/UH/02383). The young people gave written consent for their interview and verbally agreed to it being recorded. Pseudonyms used to protect the participants' identities.

\section{Findings}

Activity logs

Activity logs that fulfilled the ethical criteria were completed by nine $(36 \%)$ of the NHSEYF members aged between 15 and 22 years. Of the respondents $44 \%$ $(n=4)$ were male and $56 \%(n=5)$ were female, $78 \%(n=7)$ were still in education and four had other additional roles and responsibilities either paid $(22 \% ; n=2)$ or volunteer $(22 \% ; n=2)$. Six respondents were involved in other organisations as well as the NHSEYF including hospital committees, UK Youth Parliament and the Council for Disabled Children.

The respondents undertook a total of 61 activities during the three-month data collection timeframe (Figure 2). Most activities took between one and three hours. Those that took less than an hour were all concerned with telephone calls and/or email communication. Of the activities $45 \%$ took place in the home environment and other settings including: youth centres, public places, conferences, residential or educational locations. The total cost of all the activities was $£ 598$; those undertaken at home were listed as not costing anything. Young people did not claim any expenses for, for example, computer or telephone use. Costs of more than $£ 100$ were for conference attendance and those of less than $£ 100$ were related to travel expenses.

\section{Interviews}

Seven themes (participants' words indicate the focus of each one) emerged from the interviews that were undertaken with eight young people (four male and four female). Two interviewees had been members of the NHSEYF for 24 months and the other six for 12 months. One young person participated in the activity log data collection and was also involved in an interview.

The themes are presented with discussions supported by quotations taken from the participants' transcripts.

\section{The young people: 'We want to make an impact"}

The young people commented on the 'robust' (Millie) selection and recruitment process to become a member of the NHSEYF.

There was also agreement that the forum included male and female members from a range of ethnicities, backgrounds and locations. It was evident that the participants enjoyed being part of the NHSEYF and they demonstrated an enthusiastic approach to the work:

'I love it so much. It amazes me, the sheer amount of work in the services and everything that goes into patient care' (Matt).

'It's getting young people's voices across, but then for me the most key point is showing adults that young people want to have their voices heard and they're not just these kids who you can put in a children's ward and forget about' (Alastair).

The NHSEYF members participated in a wide range of initiatives and thought that there was evidence of the NHSEYF's success:

'We got everyone on Twitter to say what it is that they want. We don't just want it to be about the things that we believe are important. And the hashtag, DearNHS, made for our campaign, was a letter where we actually wrote to the NHS about transitioning and about young carers in our campaign. So, that led to board members hearing about it - you can imagine, we had a pretty big impact' (Chloe).

\section{Implications} for practice

- The NHSEYF is positively influencing healthcare and is a model that has the potential to be emulated by others

- The number of youth forums, within a healthcare context, is growing rapidly; however, the time and resources required to underpin their successful implementation and management should not be under-estimated

- Children and young people are willing, and very able, to be involved in a range of healthcare decisionmaking strategies; the opportunities, however, need to be facilitated

- A youth forum has the potential to develop health services that are informed by children and young people and are responsive to their needs 
The participants said that they had benefited from their NHSEYF membership: they spoke about their own personal development as well as their enhanced communication skills and self-confidence:

'It's improved my confidence level' (Usman).

'I developed team working skills, public speaking skills, you know, just confidence in general' (Chloe).

Motivation: 'The reasons behind why I wanted to join"

The motivation of the members to be part of the NHSEYF was primarily related to personal experiences that had led to an interest in health issues:

'I've been managing my own health and well-being...People with long-term health conditions...we've had a lot of healthcare experience' (Chloe).

However, the young people had become members of the NHSEYF for a range of other reasons: some had seen it advertised and others had had it pointed out to them by a colleague or friend. A minority thought that the NHSEYF could assist with their career goals and/or university applications, although this was never the only rationale given for joining the forum. Perhaps most importantly,

Figure 2. Summary of respondents' activities

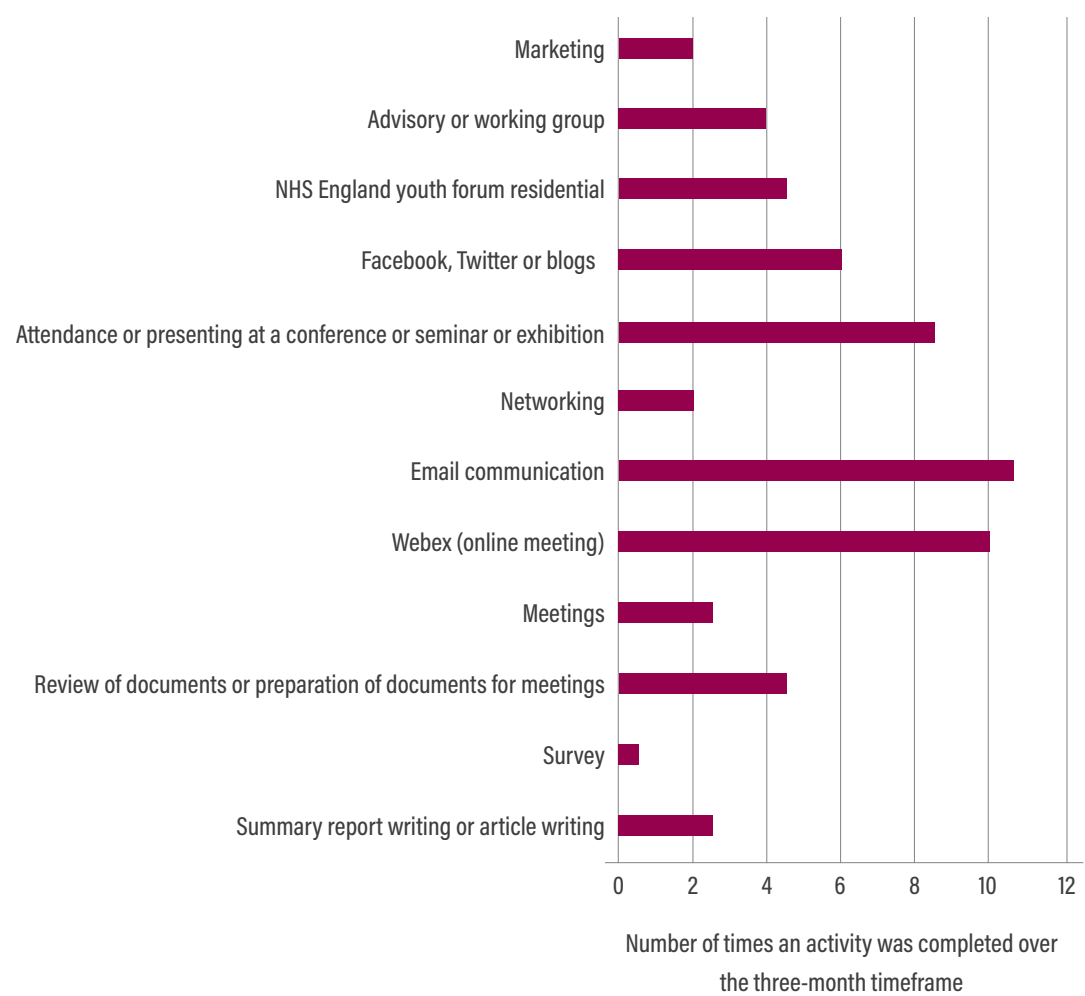

motivation stemmed from a desire to enable the voice of young people to be heard:

'Young people's voices are heard in the NHS, but they're not heard well enough... What is absolutely a testament to NHS England and to $B Y C$ is that they found young people who they know are going to be dedicated and they're going to work hard... And they are going to fight for the voices of young people and I think that's great, I really do' (Matt).

'It's about young people's voices, making an influence and making a change, improving services' (Usman).

\section{Commitment: 'You can't just say \\ "Oh, actually l'm busy""}

The participants demonstrated a strong commitment to the NHSEYF. The activity logs had indicated that the time spent undertaking NHSEYF work varied from week to week and the interviews supported this finding:

'There's no pressure to do everything. It's just, like, when you have time' (Millie).

'It varies throughout the week... I haven't even checked my emails these few weeks. But the best thing about NHSEYF is that you're never forgotten about, you're never cut off. They know that you're busy, we've got our lives, but I'm still part of the team' (Alastair).

The young people discussed the travel that was needed as part of their NHSEYF role, which included transport to the residential weekends as well as important events across England. The travel requirements could be time-consuming, meaning that they could not always attend activities.

It was agreed that it was beneficial to be an NHSEYF member for two years, as this facilitated an insight and understanding of the NHS, and provided more opportunities to be involved in initiatives. This was particularly important for those undertaking GCSE/ALevel examinations.

Community: 'You're working with a bunch of people who actually are all like-minded' An important aspect of the young people's roles as NHSEYF members involved working and collaborating with a range of people, which could be at a national or a local level. The participants had an excellent insight into the needs of their local youth community, much of which had arisen from growing up in the locality and accessing services. As a result, professional relationships had been formed with important people, such as health professionals, leaders of support groups and councillors. 
For example, Usman explained how his local knowledge had helped him to liaise with a GP practice to highlight health issues relating to young people, specifically teenage cancer and mental health. Chloe described her involvement with her local child and adolescent mental health services support group and how she had been involved with the making of a film focusing on the transition of young people to adult services.

All the members had participated in locally-based projects; as a result, there was a bidirectional dissemination of the work being undertaken. Sometimes the young people would share the initiatives they had been involved in locally at the residential weekends, for example, Chloe's film. On other occasions the national, more strategic NHSEYF activities were taken back to the young people's home locality:

'We're all working locally, but everything contributes to the national picture' (Josh).

This theme also encompassed the 'community spirit' that was fostered through the NHSEYF: the young people spoke of their commitment to common goals and the resulting friendships that had been formed:

'I $t$ 's good to have a network of friends that want similar things as you do' (Chloe).

The collegiality and friendships enabled the young people to work together on important initiatives, for example, the design and production of posters and booklets relating to young people's rights in a health context (NHS England 2016).

\section{Knowledge experts: 'They've got the NHS knowledge"}

The participants highlighted the important role of NHS England employees: they had not only been pivotal to the instigation and implementation of the NHSEYF, but they also had expert knowledge of the NHS. This expert knowledge provided the NHSEYF members with a muchneeded insight into the structure, organisation and policies associated with NHS England:

'You're actually learning a lot more about the structure and the framework of the NHS and how things operate and... it's rewarding that professionals are listening to you and you can have those mutual conversations even though you're at completely different age levels. You know, that doesn't matter, you're still listened to and valued' (Georgia).

The knowledge and insight that the NHS employees were able to impart to the young people meant that their confidence grew:

'It's essential to have people from the NHS working with us, they give us knowledge and confidence' (Charlotte).
The participants highlighted the facilitative approach that was nurtured by the NHS employees, which in turn enabled the forming of a professional partnership approach that had the common aim of listening to the voice of young people.

\section{Youth workers: 'They've supported me'} The NHSEYF members all discussed the guidance, advice and support that had been given by the BYC youth workers. Their role focused on the daily management of the NHSEYF with communication being central. A range of different approaches was drawn on, which included email, telephone and face-to-face discussions. Despite this, the main and most popular communication methods were the Wednesday Weekly, an electronic newsletter, and the closed Facebook page; these methods were used to provide details of forthcoming events as well as to ask the members for their opinions.

The participants were extremely positive about the youth workers and the support that they provided. The members had all developed a good rapport with them, meaning that they felt able to ask questions or share any anxieties or worries:

'You want to do something you just ring them up, you call them and they will give you advice, they will tell you which way to go' (Josh).

'The fantastic experience that you get from them... It is absolutely fantastic and their youth work, their capabilities and knowledge comes into this. It works well' (Matt).

\section{Funding: 'All my expenses are paid'}

The young people were aware that funding was required to underpin the running of NHSEYF. However, they did not demonstrate understanding of the details. The participants had not had any challenges in terms of claiming travel costs, but Alastair mentioned that he thought that it would be 'a bit expensive' to stay overnight so he tried to go to events that were manageable in a day.

In relation to payment for their time, there was absolute agreement by the young people that this was not required:

'It's for the better of young people, so I don't want to be paid' (Alastair).

The interview data demonstrated that the NHSEYF members were extremely motivated and committed to their role and to enabling the voice of young people to be heard.

\section{Discussion}

One of the main findings from the studies by 
Matthews (2001) and Collins et al (2016) was that the needs of local communities were being met through the work of youth councils. This study concurs with those findings, but the national nature of the NHSEYF has meant that the positive effect has also been strategic and broader. For example, the booklet and posters reflecting young people's rights in healthcare (NHS England 2016) have been widely distributed to professionals across England. The tokenism, lack of authority and not being wholly representative of young people's views highlighted by Matthews (2001) did not emerge from the NHSEYF members. The positivity of the young people may have been facilitated, at least in part, by the knowledge experts and youth workers who they felt were committed to enabling the voice of young people to be heard. This study highlighted the diversity of the NHSEYF members, which Matthews (2001) and Collins et al (2016) identified as not being evident in their research.

Many of the participants in this study had been involved in other volunteer initiatives in their local community, some of which were health related, and this work had prompted several of them to apply to join the NHSEYF. As a result, the members had previous knowledge of volunteering and recognised the need for a committed and motivated approach. In addition, it meant that there was a two-way dissemination of the NHSEYF work that they were undertaking with national initiatives being applied at a local level and vice versa.

Shantz et al (2014) commented on the 'internal push' that underpins volunteering. They suggested that organisations should facilitate the development of strong and positive relationships between the volunteers and the recipients of their work: the volunteers are then able to see the effect of their commitment and are then likely to be motivated to undertake more activities. This was the case with the NHSEYF: members commented on their common goals and the friendships that they had formed. In addition, they spoke enthusiastically about the initiatives that they had been involved in and their effect. However, it is also important to acknowledge the funding required to support a youth forum as this is a fundamental resource. Finances are inevitably required, which may not just include the cost of venue hire, refreshments and travel, but can also mean that there are expenses associated with the implementation of initiatives as well as staff time. The members of the NHSEYF had any expenses paid, such as travel, food and accommodation, but none of them wanted any personal remuneration for their time commitment - this was given freely, willingly and with enthusiasm.

According to Ballard (2014), motivation can be categorised into four areas:

" Personal issue or cause captures issues that the individual young person is passionate about.

॥ Belief suggests that motivation stems from a specific belief about the cause.

॥ Self-goal relates to self-development and enhancement.

» Response to an invitation.

This was certainly true with the NHSEYF: the young people expressed how much they had enjoyed their membership. Their participation had facilitated their personal growth and led to the meeting of local and national objectives. In addition, while there were many reasons why the young people joined the NHSEYF, for example, personal healthcare experiences or it was thought to facilitate future career or university aspirations, motivation always came from the need to ensure that young people's voices were listened to.

\section{Limitations}

Nine $(36 \%)$ of the 25 NHSEYF members completed activity logs. While the response rate was low, the data remain valuable and may be no different from those obtained from a higher return rate (Keeter et al 2006). Strategies such as email reminders were used to try to increase the number of completed logs as suggested by Nulty (2008). Selfreporting can also be associated with response bias (Polit and Beck 2012) and information in the activity logs may not have been wholly accurate.

The sample did not include all members of the NHSEYF and therefore the findings may not be wholly representative of all members.

Just one person who completed an activity $\log$ was also involved in a semi-structured interview; nevertheless, it is important to acknowledge that some data were obtained from 16 of the 25 NHSEYF members - it may mean that the young people were willing to engage with one method, but not another.

\section{Recommendations for future research}

Two recommendations for further research are:

» Research involving health professionals to gain insight into their understanding of the NHSEYF and how its work may influence their practice.

" Consideration of how the NHSEYF could embrace the wider children and young people's community. 


\section{Conclusion}

This research was the first to evaluate a national youth forum in England. Aspects of the findings concur with some existing literature that relates to young people's participation, however, new insights are offered. The most notable are the key composite areas that support a successful youth forum: the young people themselves, their motivation and commitment, their familiarity with their local community and their community spirit, the knowledge experts, youth workers and funding.

While the Care Quality Commission (2017) survey of 132 acute NHS trusts reported some positive findings in relation to the
Pseudonyms have been used to protect the participants' identities.

experiences of children and young people, areas for improvement were highlighted, for example, $36 \%$ of children aged eight to 11 years said that they did not always understand the information given to them by staff.

The number of youth forums continues to grow and they undoubtedly play an important role in representing the views of children and young people as well as enhancing health service provision. The findings from this study may provide insight to others who are establishing or facilitating a youth forum in a health context.

\section{References}

Ballard PJ (2014) What motivates youth civic involvement? Journal of Adolescent Research. 29, 4, 439-463.

Care Quality Commission (2017) 2016 Children and Young People's Inpatient and Day Case Survey Statistical Release. cqc.org.uk/sites/default/ files/20171128_cyp16_statisticalrelease.pdf(Last accessed: 25 May 2018.)

Clandinin DJ, Connelly FM (2000) Narrative Inquiry: Experience and Story in Qualitative Research. Jossey-Bass, San Francisco CA

Collins ME, Augsberger A, Gecker W (2016) Youth councils in municipal government: examination of activities, impact and barriers. Children and Youth Services Review. 65, 140-147.
Creswell JW (2012) Educational Research: Planning, Conducting, and Evaluating Quantitative and Qualitative Research. Fourth edition. Pearson, Boston MA.

Greene JC, Caracelli VJ, Graham WF (1989) Toward a conceptual framework for mixed-method evaluation designs. Educational Evaluation and Policy Analysis. $11,3,255-274$.

Keeter S, Kennedy C, Dimock M et al (2006) Gauging the impact of growing nonresponse on estimates from a national RDD telephone survey. Public Opinion Quarterly. 70, 5, 759-779.

Matthews H (2001) Citizenship, youth councils and young people's participation. Journal of Youth Studies. 4, 3, 299-318.
Moule P, Goodman M (2014) Nursing Research: An Introduction. Second edition. Sage, London.

NHS England (2015) NHS England and the British Youth Council. Bitesize Guide to Setting up a Youth Forum in Health Services across England. NHS, London.

NHS England (2016) Youth Forum Youth Rights in Healthcare Posters. www.england.nhs.uk/ participation/get-involved/how/forums/nhs-youthforum (Last accessed: 25 May 2018.)

Nulty DD (2008) The adequacy of response rates to online and paper surveys: what can be done? Assessment \& Evaluation in Higher Education. $33,3,301-314$.
Palinkas LA, Horwitz SM, Green CA et al (2015) Purposeful sampling for qualitative data collection and analysis in mixed method implementation research. Administration and Policy in Mental Health. 42, 5, 533-544

Polit DF, Beck CT (2012) Nursing Research: Generating and Assessing Evidence for Nursing Practice. Ninth edition. Lippincott Williams and Wilkins, Philadelphia PA

Shantz A, Saksida T, Alfes K (2014) Dedicating time to volunteering: values, engagement, and commitment to beneficiaries. Applied Psychology. $63,4,671-697$. 